\title{
Determinants of Awareness about of Mental Health Care Act 17 to be Integrated into Primary Health Care System at King Sabata Dalindyebo Municipality
}

\section{Dlatu Ntandazo ${ }^{1}$, Longo-Mbenza Benjamin ${ }^{2^{*}}$ and Malema Isaac ${ }^{3}$}

${ }^{1}$ Mthatha General Hospital, CEO'S Office, Mthatha, South Africa

${ }^{2}$ Walter Sisulu University, Faculty of Health Sciences, Mthatha, South Africa

${ }^{3}$ School of Public Systems and Public Health, University of Pretoria, Mthatha, South Africa

*Corresponding author: Longo-Mbenza Benjamin, Research Champion Professor, Faculty of Health Sciences, Walter Sisulu University, Private Bag X1, Mthatha 5117, Eastern Cape, South Africa, Tel : +27732822483; E-mail: longombenza@gmail.com

Received date: March 12, 2014, Accepted date: September 1, 2014, Published date: September 10, 2014

Copyright: (c) 2014 Longo-Mbenza Benjamin, et al., This is an open-access article distributed under the terms of the Creative Commons Attribution License, which permits unrestricted use, distribution, and reproduction in any medium, provided the original author and source are credited.

\section{Abstract}

Background: Primary Health care refers to care which is based on the needs of population. From the promulgation of Mental Health Act 17 of 2002 in South Africa, there is no research in King Sabata Dalindyebo [KSD], carried out on issues around integration of mental health with primary health care.

Objective: The aim of the study was to investigate the level and determinants of awareness about Mental Health Act 17 in KSD

Methods: This cross-sectional study was conducted between January 2010 and December 2011. A representative sample recruited 52 health professionals who were approached and agreed to participate in the study clinics. Measure outcomes were demographic characteristics, education/ qualifications, general and further training in psychiatry, awareness about Mental Health Care Act 17 of 2002 and mental health care services characteristics.

Results: A total of 52 health professionals (40.4\% males, 59.6 females, 59.6 married, 3 doctors, 49 nurses, mean age $36.9 \pm 8$ years range from 23 years to 52 years), were surveyed with $57.7 \%$ ( $n=30$ ) with awareness about Mental Act 17. Age did not influence awareness about Mental Act $17(37.7 \pm 7.1$ years vs. $36.3 \pm 8.7$ years; $\mathrm{P}=0.545)$. However, working in advantaged clinics ( $90 \%$ vs. $38 \%$ in disadvantaged clinics; $\mathrm{P}<0.0001)$, postgraduate diploma in psychiatry ( $86 \%$ vs. $47 \%$ in lower education), presence of coordinator in charge of training and auditing at the district level (72\% vs. $44.4 \%$ in absence), and organization on workshops about Mental Health Act $17(71.9 \%$ vs. $35 \%$ in lack) were the significant contributing determinants of awareness about Mental Health Act 17.

Conclusion: There is a lack of implementation of Mental Health Act 17 to be integrated at primary health care and in improving human capacity for mental health in terms of continuous training in mental health issues, policies, organization and development.

\section{Keywords:}

Mental health; Integration; Primary care; Determinants; South Africa

\section{Introduction}

World Health Organization advocated for the Integration of Mental Health into Primary Health Care because hundreds of millions of people, including men, women, children, poor and rich, are affected by mental disorders [1,2]. Depression, Schizophrenia, Suicide, Alcohol Abuse, Alzheimer's disease, Epilepsy and Dementia are the most frequent [3]. Over the last 25 years, several programmes of Integration of Mental Health into Primary Health Care have been initiated to improve psychiatric services in the developing countries such as SubSaharan Africa including South Africa, our country [4-17]. After 10 years of the Freedom Event in 1994, the new South African democracy provided the Mental Health Care Act 17 of 2002 (MHCA) in 2004 [18]. Indeed, South Africa promulgated the Mental Health Act 17 of 2002 had immediately effect in 15 December 2004. This Act 17 along with associated General Regulations published on the same day. The positive language in both the Act and Regulations help to address the stigma traditionally to mental health care users and their health care services providers.

However, mental illness is still the major cause of morbidity as well as some mortality particularly among citizens at risk in South Africa [19]. The latter refers specifically to communities which have for decades, been ravaged by the state neglect and abuse. Generally, mental health promotion and provision of services to South African communities have been neglected in the past [19].

On clinical impression, it has been evident that mental health users coming from surrounding areas of King Sabata Dalindyebo Municipality [tertiary referral psychiatric service in Mthatha] have a high rate of re-admissions due to unavailability of treatment. In most cases they travelled long distances to access mental health care services including continuation treatment after discharge from Mental Health Hospital.

There is no information about the knowledge of Mental Health care Act 17 related to the characteristics of health professionals in KSD. There is a need to generate evidence of the effectiveness of 
interventions operating at different levels at KSD according to South Africa Act [18] and from policy to practice, a framework for delivery of district mental health care in Kwazulu Natal Province [20].

Therefore, the objective of this study was to investigate the level and determinants of awareness about Mental Health Act 17 in KSD.

\section{Methods}

This cross-sectional design was carried out from January 2010 to December 2011.

The researchers have been given permission to conduct the study by Sub-district Manager of King Sabata Dalindyebo and Eastern Cape Department of Health. On approval by ethical committee of Walter Sisulu University, Mthatha, South Africa, the informed consent letters were sent to the participants explaining about the study. A representative sample recruited 52 health professionals (10\% random sample out of the list of all 520 health workers in KSD) who were approached and agreed to participate in the study clinics. Confidentiality of information of the participants was maintained and kept anonymously. Then, the study was conducted according to Helsink Declaration at King Sabata Dalindyebo Sub-district Clinics, Mthatha, Eastern Cape, South Africa. King Sabata Dalindyebo is one of seven local municipalities located within OR Tambo District Municipality in the Eastern Cape Province. It comprises four amalgamated entities comprised of both Mthatha and Mandela urban and rural magisterial areas. It measures approximately $3019 \mathrm{~km}$ square in extent and approximately has 430000 people in the municipal area, the majority of whom reside in rural settlements. The city of Mthatha is an important regional service centre and tourism gateway city. Mqanduli is subsidiary node, with other nodes and development areas along the coast, and mountain region to the north.

The population is primarily dependant on welfare and pensions for their survival due to widespread of poverty and unemployment. The municipality has forty seven health facilities referring to one Mthatha Hospital which comprises of general hospital and within mental health unit, Nelson Mandela Academic Hospital and Bedford Orthopaedic Hospital. These health facilities consist of forty two clinics, four community health centres and one mobile clinic. The coordinator is the officer in charge of Mental Health Services such as auditing, training, supervising health workers and implementing Mental Health Act 17 across KSD.

The representative sample of the study was included on the following criteria: inclusion criteria effective presence during the survey and exclusion criteria (refusal to participate and absence at work due to leave and sickness). The response rate was $100 \%$ out all 52 recruited health professionals.

Pre-tested, Pre-coded, Structured and standardized closed ended questionnaires were used and administered during 30 minutes as tool to collect data on each participant. The questionnaire was piloted on 10 health professionals. Based on the findings from the pilot, the questionnaire was adapted and revised. The language used was English spoken by participants.

Forty three questions, administered, dealt with socio-demographic data, knowledge of the Act 17 of 2002 [18], training capacity, availability of drugs and transport, condition of infrastructure, specialised personnel and attitudes of health professionals towards mentally ill.
The correct procedures and quality of measurement procedures have been applied to find the answers to a question for example the tools were tested to the participants but they gave same responds twice. The interview schedules were done by the researcher himself (ND) for clarity to the respondents. The tools also were further handed over to research champion (LMB) to identify if all aspects pertaining to the topic were addressed and relevant for the study.

To reduce selection, information and biases that are due to confounding, the researcher has informed the participants to ensure continued participation as well as prevention of participant and researcher exhaustion.

\section{Definitions}

The integration of mental health defined by Elizabeth Amstrong [21] was including screening, prevention, early intervention and treatment of diseases at primary health care level [22].

High or low levels of awareness about Mental Health Act were defined among $>=60 \%$ or $<60 \%$ among the study population.

\section{Statistic analysis}

The variables were characterised using frequency [n] and proportion [\%] for qualitative [categorical] data, and mean \pm standard deviation of ages. The proportions between 2 groups [Awareness Yes vs. No] were compared using chi-square test. Student-t test were used to compare means \pm standard deviation $[\mathrm{SD}]$.

$\mathrm{P}$-value $<0.05$ was considered as statistically significant difference. All analyses were performed using Statistical Package for Social Sciences [SPSS] version 21 for Windows [IBM SPSS Inc, Chicago, IL, USA].

\section{Results}

A total of 52 health professionals (40.4\% males, 59.6 females, 59.6 married, 3 doctors, 49 nurses, mean age 36. $9 \pm 8$ years, range from 23 years to 52 years) were surveyed.

The majority were professional nurses [females], contrasting with 2 female medical doctors and 1 male medical doctor.

The frequency rate of awareness about Mental Health Act 17 of 2002 was $57.7 \%$ [ $n=30$ with low level] out of all professionals surveyed in the study.

\section{Determinants of awareness about mental health care Act 17 of 2002}

Professionals working in advantaged clinics were significantly more $(90 \% \mathrm{n}=18 / 20)(\mathrm{P}<0.0001)$ aware about mental health care Act 17 of 2002 than their counterparts working in disadvantaged clinics $(38 \%$ $\mathrm{n}=12 / 32$ ).

Awareness about mental health care Act 17 of 2002, was significantly lower among workers with low education qualification (high school, undergraduate diploma and degree: $47 \% \mathrm{n}=18 / 38$, $\mathrm{P}=0.037$ ) than in their counterparts with highest educational qualification with postgraduate diploma in psychiatry $(86 \% n=12 / 14)$.

Workers who reported the presence of co-ordinator for mental health services were significantly more aware $(72 \% n=18 / 25, P=0.044)$ about mental health care Act 17 of 2002 than those who did not reported $(44.4 \% \mathrm{n}=12 / 27)$. 
Awareness about mental health care Act 17 of 2002 was significantly commoner $(71.9 \% \mathrm{n}=23 / 32, \mathrm{P}=0.009)$ among workers who reported the presence of workshop on mental health care Act 17 of 2002 than in those who did not $(35 \% \mathrm{n}=7 / 20)$.

\section{Discussion}

This study outlined major findings which were discussed in relation to the level and determinants of the awareness about Mental Health Act 17 in KSD. This study showed a low level of knowledge and implementation of Mental Health Act 17 and care services to be integrated into primary health care system in KSD Sub-district municipality, OR Tambo District, Mthatha, Eastern Cape Province of South Africa. Indeed, the study showed that integration of mental health care services into primary health care system was not optimal, despite the dismantled of the apartheid practices, the trials and triumphs about Mental Health Care Act No. 17 in South Africa [7].

\section{Socio-demographic profile}

In this study there was a female predominance [Sex ratio almost 2 females: 1 male]. In South Africa, the demographics encompass about 50 million people of diverse origins, cultures, languages and religions, the sex ratio is almost 1 male: 1 female [CIA World Fact book, [en.wilkipedia.org/ wiki/List of countries] List of Countries by sex [23].

It is important to recognise the profound implications of genderbased inequities in health. Evidence is emerging that integrating gender considerations into interventions has a positive effect on health outcomes across various domains [24].

However; the majority of female health workers were professional nurses and not at top level. Indeed, only 2 women were medical doctors and contracted Implementation of South African affirmative policies and measures has resulted in better equity in gender representation in the public sector management [25]. Reasons for their dominance in the nursing and supplementary professions are historical and international phenomenal [25].

In Zambia, Nurses are the frontline staff in delivery of mental health care in primary health care units in both long stay facilities and daily outpatient facilities [26].

Globally the participants were young adults. Moreover, females were older than males. These mean ages were similar with those reported among Zambian mental health professionals [26].

Barriers to mental health care integration in primary health care system in King Sabata Dalindyebo Municipality.

The present study explored challenges of integration of mental health into primary health care from the perspective of health professionals in King Sabata Dalindyebo Municipality.

It identified the key barriers around integrating mental health care into primary health care as follows: under representation of further training in psychiatry [specialization]; low awareness about mental health care Act 17 of 2002 [18]; low levels of documentation, provider training and support, entry or admission, training psychiatric sister for supervision of mental health care services; the majority not aware about how often out-reach programmes for mental health are organised; almost $100 \%$ of referrals to tertiary levels; mental disorders are provided only by medical officer; lack of implication of regional psychiatrist; lack of visit by mental health specialist, psychologist and social worker; poor accessibility to Mthatha hospital for tertiary level of majority of disadvantaged clinics; restrictions that prohibit primary health care nurses from prescribing common psychotropic medication [7].

These main constraints of integrating mental health into primary health care system are not full taken into account worldwide [26-29].

The lack of awareness about the mental health care Act 17 of 2002 [18] and other identified barriers could undermine the successful implementation of the mental health care integration into community mental health system $[18,29,30]$. The determinants of the lack $[18,29,30]$ of awareness about mental health care legislation in South Africa were also identified in the survey. These determinants, related to poverty, lack of infrastructure, inadequate skills and training as well as poor support from the government, included: professionals working in disadvantaged clinics; health workers with low educational qualification; lack of co-ordinator for mental health care services; absence of workshops on mental health care Act 17 of 2002 [18].

These findings witness that the South African mental health care Act 17 of 2002 [18,29], is no longer against apartheid legislature on mental ill patients and against a backdrop of positive international developments in mental health legislature [18]. Apartheid for legislation was reinforcing the alienation, stigmatization and disempowerment of mental ill patient in South Africa. To reduce this gap, Burns offered the solution of translating principles into practice [29].

\section{Potential factors to implementing integration of mental health into primary health care system}

The present survey showed relevant factors with potential implementation of integrated mental health care into primary health care system. Indeed, the characteristics of mental health care services were reported by health workers to be good to excellent.

The retention of the surveyed health professional within the remote areas of King Sabata Dalindyebo, possible related to high proportion of married health professionals, should the cornerstone of integration of mental health services into primary health care system.

These characteristics constitute the rationale for integrating mental health care service into primary health care system with the following advantages [22] decreased stigma in mental patients; improved of accessibility to mental health care services and comorbidity physical conditions; respect of confidentiality and human rights; effectiveness of mental health care services; availability of treatment, support environment, emergency care; screening, service management and development; mental health promotion, psycho social rehabilitation; language, cultural context, community living; telephone, fax machines, medication; transport offered to patients.

\section{Implications and perspectives for public health and Implementation of Health}

The present data will impact in rendering integrated primary mental health services as complementary with tertiary and secondary level of mental health care services in King Sabata Dalindyebo and other developing Sub-districts.

Of the World Health Organization, proposes the development of community based mental health services worldwide [28]. Even in 
developed countries, primary health care based mental health services are preferred in contrast to more hospital based services [28].

This study will have implication for health care provision and use [making mental health care service available, accessible and acceptable in King Sabata Dalindyebo], implication for health policies [enhancement of current South African mental health policy can be successful integrated into primary health], and implications for further research (mental health services and mental health economies, perceptions of health workers, predisposing, enabling factors associated with successful integration of mental health into primary health care system).

The present data will serve to break the vicious cycle of human poverty and mental ill-health, in order to generate lessons provided by poor setting [13,23-25].

The present information emphasises on the importance of effective mental health services as South Africa is facing a burden of diseases arising from mental health issues [26]. Cost-effectiveness of interventions for reducing the burden of mental disorders: A global analysis [26]. The mental health managers in KSD are invited to learn from the success in integrating primary care service and partnership from several developing settings out and within South Africa [27] Health care in South Africa. International Marketing Council of South Africa [14,27,28].

Ser G et al. recently reported practices of mental health workers using electronic records [EHRs] and identified staff training among different factors that are associated to implement mental health $[30,31]$.

The factors associated with awareness legislative action about mental health care system are: remote and disadvantaged working area, lower education attainment/qualification, lack of co-ordinator for mental health service, and absence of workshops on mental health care Act 17 of 2002 .

There is a lack of improving human capacity for mental health in terms of continuous training in mental health issues, policies, organization and development. The main premise of Mental Health Act 17 appears to be grounded in ensuring that mental ill patient receive the least restrictive intrusive intervention [31]. If HER systems are to be used efficiently in South Africa, Policy should not shift from demise of the Government.

Additionally, successful interventions at KSD need to delivered with Transformation of Health system based on equity, improved human resources and management capacity, merit of health workers and continuous tract at achieving Millennium Development Goals 4, 5, and 6 for better lives of South Africans [32].

This information may also assist the KSD health system in monitoring implementation and identify ways to support frontline health wokers in delivering high quality services to mental ill patients [33].

\section{Limitations}

The study was limited to some degree using the cross-sectional design and a small size.

\section{Conclusion}

The awareness about the mental health care Act 17 of 2002 was low among Health workers in KSD. Globally, the integration of mental health care service in King Sabata Dalindyebo is non-optimal.

To close this gap, urgent interventions on the determinants of low awareness are needed.

\section{References}

1. WHO (2007) Integrating Mental Health into Primary Health Care. Geneva, World Health Organization.

2. WHO (2001) World Health Report 2001, mental health new understanding, new hope, World Health Organization.

3. World Health Organization (1984) Mental Health Care in developing countries. A critical appraisal of research findings, WHO: Geneva.

4. Shah A, Jenkins R (1999) Mental health economic studies from developing countries reviewed in the context of those from developed countries. Acta Psychiatric Scandi 100: 1-18.

5. Kigozi F (2007) Integrating Mental Health into Primary Health CareUganda's experience. South African Psychiatry Review 10: 17-19.

6. Schulsinger F, Jablensky A (1999) The national mental health programme in the United Republic of Tanzania. Report from WHO and DAVIDA. Acta Psychiatr Scand Suppl 364: 1-32.

7. Ramlall S (2012) The Mental Health Care Act No 17- South Africa. Trials and Triumphs: 2002-2012. African Journal of Psychiatry [Johannessburg] 15: 407-410.

8. Kanye F, Chiwandira C, Wright J (2012) Increasing the capacity of health surveillance assistants in community mental health care in a developing country, Malawi. Malawi Medical Journal 23: 85-88.

9. Petersen I, Lund C, Bhana A, Flisher AJ (2012) Mental Health and Poverty Research Programme Consortium. Health Policy Plan 27: 42-51.

10. Bhana A, Petersen I, Baillie KL, Flisher AJ (2010) The MHAPP Research Programme Consortium. Int Rev Psychiatry 22: 599-610.

11. Ssebunya J, Kigozi F, Kizza D, Ndyanabangi S (2010) MHAPP Research Programme Consortium. African Journal of Psychiatry [Johannesburg] 13: $128-131$

12. Jansen van Rensburg AB (2009) A change climate for mental health care delivery in South Africa. African Journal of Psychiatry [Johannesburg] 12: 157-165.

13. Petersen I, Bhana A, Campbell-Hall V (2009) Planning for district mental health services in South Africa: a situational analysis of a rural district site. Health Policy Plan 24: 140-150.

14. Burns JK (2008) Implementation of the Mental Health Care Act [2002] at district hospital in South Africa: Translating principles into practice. South African Medical Journal 98: 46-49.

15. Breen A, Swartz I, Flisher AJ (2007) Experience of mental disorder in the context of basic service reforms: the impact on caregiving environments in South Africa. International Journal of Environmental Health Res 17: 327-334.

16. Odejide AO, Morakinyo JJ, Oshinama FO, Omigbodun O, Ajuwon AJ (2002) Integrating mental into primary health care in Nigeria: management of depression in a local government [district] area as a paradigm 104: 802-809.

17. Sokhela NE, Uys IR (1999) The integration of comprehensive psychiatric/ mental health care into the primary health system: diagnosis and treatment. Journal of Advanced Nursing 30: 229-237.

18. National Department of Health No. 17 of 2002: Mental Health Care Act, 2002. Cape Town Government Gazzett 2002: 79.

19. Lund C, Flisher AJ, Lee T, Porteus K, Robertson BA (2000) A model for estimating mental health service needs in South Africa. South African Medical Journal 90: 1019-1024. 
Citation: Dlatu, Longo-Mbenza and Malema (2014) Determinants of Awareness about of Mental Health Care Act 17 to be integrated into Primary Health Care System at King Sabata Dalindyebo Municipality. J Psychiatry 17: 1000139. doi:10.4172/2378-5756.1000139

Page 5 of 5

20. Peterson I, Bhagwamjee A, Parekh A (2000) From policy to praxisframework for the delivery of district mental health care in KwazuluNatal. South African Medical Journal 8:798-804.

21. Amstrong E (1995) Mental Health Issues in Primary Care: A Practical Guide. London, 1995, Macmillan Press Ltd.

22. Flannigan CB, Glover GR, Wing JK, Lewis SW, Bobbington PE, et al. (2005) Inner London collaborative audit of admission to two health district iii: Reasons for acute admission to psychiatric wards. Britain Journal of Psychiatr 165: 750-759.

23. Saraceno B, Van Ommeren M, Batniji R, Cohen A, Gureje O, et al. (2007) Barriers to improvement of mental health services in low-income and middle-income countries. Lancet 370: 1164-74.

24. Boarder C, Santana D, Santilla ND, Hardse K, Greens ME, et al. The "So What" Report : A look at whether Integrating a gender focus into programs makes a difference to outcomes. Washington: Interagency Gender Working Group Task Force Report.

25. World Mental Health Day. Mental Health in Primary Care: Enhancing Treatment and Promoting Mental Health, 10 October 2009.

26. Mwape L (2010) Integrating mental health into primary health care in Zambia: a care provider's perspective. International Journal of Mental Health System 4: 21.

27. Williams DR (2008) Twelve-month mental disorders in South Africa: prevalence, service use and demographic correlates in the population- based South African Stress and Health Study. Psychological Medicine 38: $211-220$

28. World Health Organization. Mental health care in developing countries, 1984. A critical appraisal of research findings [WHO]: Geneva.

29. World Family Doctors, World Health Organization. Integrating mental health services into primary health; Mental Health Policy, Planning and Service Development, 2008: Integrating Systems and Services, Integrating People.

30. Randolph FL, Ridgeway P, Carling PJ (1991) Residential programmes for persons with severe mental illness: a nationwide survey of state-affiliated agencies. Hospital Community Psychiatry 42: 1111-1115.

31. Ser G, Robertson A, Sheikh A (2014) A Qualitative Exploration of Workarounds Related to Implementation of National Electronic Health Records in Early Adopter Mental Health Hospital. PLOS ONE 9: e77669.

32. Mayosi BM, Lawn JE, van Niekerk A, Bradshaw D, Abdool Karim SS, et al. (2012) Health in South Africa:changes and challenges since 2009. Lanct 380: 2029- 2043.

33. Beehler GP, Funderbuk JS, Possemoto K, Vair CL, Developing a measures of provider adherence to improve the implementation of behavioural health services in primary care: a Delphi study. 